\title{
AS RELAÇÕES DE TRABALHO NO MARANHÃO: expressões da dinâmica do desenvolvimento dependente
}

\author{
Zaira Sabry Azar \\ Universidade Federal do Maranhão (UFMA) \\ Francisco Elias de Araújo \\ Movimento dos Trabalhadores Rurais Sem Terra (MST)
}

\begin{abstract}
AS RELAÇÕES DE TRABALHO NO MARANHÃO: expressões da dinâmica do desenvolvimento dependente Resumo: O trabalho aborda o desenvolvimento dependente na Amazônia maranhense, destacando a inserção do estado do Maranhão na dinâmica de desenvolvimento econômico brasileiro, cujo modelo adotado apresenta características de dependência e sem autonomia política ou econômica. Atribui destaque ao papel histórico assumido pela economia maranhense na divisão nacional e internacional do trabalho e, em particular, nas transformações contemporâneas da mundialização do capital, apreendendo os processos de trabalho constituídos. Explica as relações sociais construídas, no Maranhão, tanto no passado quanto hoje, a partir da inserção subordinada desse estado à dinâmica global do capital. Nesse sentido, enfatiza que a compreensão das transformações acontecidas no mundo do trabalho, e de forma especial, nas relações de trabalho nessa unidade federativa, exige compreender o papel por esta assumido na totalidade do desenvolvimento capitalista. O texto, por fim, considera que as relações de trabalho sofrem determinação histórica e têm como base as contradições inerentes ao modo de produção capitalista, como a necessária reprodução de formas não capitalistas de produção, a exemplo do campesinato.
\end{abstract}

Palavras-chave: Desenvolvimento dependente, relações de trabalho, Maranhão.

LABOUR RELATIONS IN MARANHÃO: expressions of the dynamic of dependent development

Abstract: The work addresses the dependent development in Maranhão Amazon, highlighting the inclusion of the state of Maranhão in the dynamic Brazilian economic development, whose adopted model presents with dependence characteristics and without political or economic autonomy. The text highlights the historical role played by Maranhão economy in the national and international division of labor and, in particular, in contemporary transformations of capital globalization, seizing work processes constituted. In Maranhão, social relationships built, both past and today, are explained here from their conditional inclusion on the global dynamics of capital. In this sense, emphasizes the changes taken place in the working world, and in a special way, in labor relations in this federal unit, it is necessary to understand the role that the state took over the whole of capitalist development. The text considers that labor relations suffer historical determination and are based on the contradictions inherent in the capitalist mode of production as the necessary reproduction of non-capitalist forms of production, such as the peasantry.

Key words: Dependent development, labor relations, Maranhão. 


\section{INTRODUÇÃO}

O desenvolvimento, de forma geral, constitui debate de muita polêmica e que nos exige profundas reflexões. O Brasil, em sua trajetória histórica, tem adotado os modelos de desenvolvimento econômico defendidos pelos grandes centros econômicos fundamentados na acumulação do capital.

Cumprindo papel importante na divisão internacional do trabalho, o país centrou sua produção, incialmente, no modelo agroexportador para abastecimento do mercado internacional. Posteriormente, buscou se firmar como economia industrializada, com base em uma indústria considerada atrasada frente aos processos industriais e tecnológicos existentes na economia internacional. Atualmente, se revela excelente na produção de grandes commodities, principalmente, os agrícolas e minerais, ou seja, o país intensifica seu papel de produtor de matéria-prima na dinâmica da industrialização global.

Com isso, podemos considerar que as proposições históricas de desenvolvimento defendidas pelo Estado brasileiro assumem caráter essencial de dependência, posto que todos os modelos atrelam a economia nacional à dinâmica da macroeconomia, onde as deliberações econômicas nacionais encontram-se articuladas ao contexto político das grandes potências mundiais, sofrendo de forma contundente as consequências dos jogos de interesses dos grandes projetos societários.

Assim, articulado aos movimentos políticos e econômicos de outros países, o Brasil mantémse numa condição de extrema vulnerabilidade, não tendo conseguido construir sua autonomia para decidir sobre o tipo e forma de desenvolvimento que lhe convém. Longe de uma soberania nacional, organiza sua produção, de forma geral, de acordo com a organização do capital internacional, ainda que esta rebata nas relações de trabalho de maneira a afetar direta e negativamente o conjunto dos trabalhadores nacionais, comprometendo, portanto, o futuro da sociedade brasileira como um todo.

O Estado do Maranhão não foge à dinâmica global e, seguindo à lógica do desenvolvimento nacional, desencadeou, historicamente, processo produtivo submetido aos interesses e necessidades do capital internacional. Com a insistente retórica do desenvolvimento, esta unidade federativa viveu ciclos produtivos importantes na divisão nacional e internacional do trabalho desde o período colonial. Invariavelmente, as relações de trabalho foram sendo reconfiguradas a partir dos diferentes contextos produtivos, sendo que no estado foi constituído um padrão de uso da força de trabalho baseado na exploração intensa, precárias condições e expropriação dos meios e condições de trabalho, a exemplo, bem explícito, das famílias camponesas que sempre sofreram as consequências das dinâmicas e ciclos produtivos com a instalação de conflitos, violência, expropriação e expulsão das terras.

Dos muitos projetos econômicos desenvolvidos no estado, hoje, tem hegemonia produtiva, iniciativas do agronegócio, ainda que se apresente com destaque a indústria, cuja produção encontra-se voltada, essencialmente, para a produção de matéria-prima.

O agronegócio tem como suas maiores expressões o monocultivo de soja, eucalipto, bambu, cana-de-açúcar, mas também, encontra-se organizada no estado, com grande peso econômico, a pecuária extensiva e a cacinocultura. Tudo isso numa articulação direta com a extração de minérios, ouro e gás, além das hidrelétricas e centro aeroespacial.

No contexto de reestruturação do capital, invariavelmente, estes projetos reconfiguram as relações de trabalho, impondo aos proprietários da força de trabalho, condições de precarização destas relações, expressas, principalmente na terceirização e informalidade, o que têm comprometido a própria reprodução social de grupos e categorias de trabalho.

\section{MARANHÃO NA ROTA DO DESENVOLVIMENTO DEPENDENTE}

A formação sócio histórica do Maranhão se caracteriza pela dependência a sujeitos externos, cujas relações são determinadas pela dinâmica global do capital, e constituem elementos essenciais para abordagem acerca do desenvolvimento e sua repercussão nas transformações no mundo do trabalho. Nesta perspectiva, a inserção do estado na dinâmica produtiva que emerge da criação dos Estados-nação, assume papel importante nesta dinâmica produtiva em todas as fases de sua formação, tendo destaque a atual fase imperialista do capitalismo.

No entanto, aqui destacaremos enquanto marco histórico, as contradições engedradas no pós guerra, onde o desenvolvimento industrial em escala internacional traz para o centro das disputas a industrialização de economias dependentes. O Brasil entrava na divisão internacional na dinâmica capitalista como resultado da nova forma de expansão desse sistema, elevando-se da sua fase primário-exportadora para o patamar de produtores de manufaturas.

Esta perspectiva é compartilhada por Leal (1988, p. 23), que aborda o desenvolvimento a partir da ideia de

[...] integração das economias periféricas às economias industriais; da incorporação dos avanços tecnológicos e relações da produção capitalistas pelos países dependentes. 
Articula-se com esta perspectiva de expansão capitalista a construção da concepção de desenvolvimento da Comissão Econômica para América Latina e Caribe (CEPAL), que de certo modo foi o instrumento de maior influência no pensamento econômico latino-americano, com proposição de medidas importantes como o Plano de Reabilitação da Economia Nacional, reaparelhamento industrial, Plano de Metas e Plano Trienal, que permearam o segundo governo de Getúlio Vargas (1951-1954) e de Juscelino Kubitscheck (1956-1961).

A partir da CEPAL, em 1948, estariam criadas as bases teóricas para uma relação centro periferia, ou seja, entre países industrializados com tecnologias avançadas versus países industrializados sem tecnologias, ou melhor, com tecnologias menos desenvolvidas, sendo evidenciado o atraso dos países periféricos em relação ao desenvolvimento, característica principal dos países com economia com base na produção primária. No caso, este desenvolvimento pode ser entendido como o desenvolvimento industrial, ou o desenvolvimento da economia capitalista.

No Brasil, o processo de mudança do modelo de desenvolvimento emerge, de forma particular, das transformações de 1930, considerando que a economia brasileira até então era baseada na produção agrícola voltada, essencialmente, ao mercado externo. Destarte, decorre deste período as mudanças que tornam a produção manufatureira interna o novo centro dinâmico.

Não obstante, destacamos que é importante para uma definição acerca da concepção do desevolvimento brasileiro, considerar o pensamento de Marini (2005, p. 106), que traz a ideia de "[...] integração crescente à economia capitalista internacional." Para ele esta integração

\section{[...] tem motivado uma completa inadequação da estrutura de produção à necessidade de emprego e salário das massas trabalhadoras, tudo isso não em caráter circunstancial, e como consequência da sobrevivência de reminiscências coloniais, mas sim, pela própria dinâmica do crescimento econômico em uma economia capitalista periférica. (MARINI, 2005, p. 106).}

Ao fazer esta afirmação, Marini (2005) critica a tese de Prado Jr. (2005) sobre a revolução brasileira que marca o debate do Partido Comunista Brasileiro (PCB) acerca da questão agrária, não deixando dúvidas de que no Brasil ela é prelúdio da colonização. Em outros termos, a expansão do capitalismo comercial europeu até a fase imperialista contemporânea da questão agrária tem como marco o latifúndio e a concentração. Assim, de maneira geral, temos um processo de desenvolvimento que emerge das contradições geradas do final do período agro-exportador, marcado pela reestruturação da dinâmica de acumulação ampliada do capital.

No Maranhão, o processo socioeconômico vivenciou importantes ciclos produtivos e, no que se refere ao setor industrial, já no período colonial, de acordo com Madeira (2009) a euforia se deveu à produção e exportação do arroz e do algodão, sendo esta, estimulada pela efervescente indústria têxtil inglesa. Seu declínio encontra-se atrelado à ascensão da produção estadunidense com o fim da Guerra de Secessão (1861-1865).

Para manter a economia com a queda da produção algodoeira, o estado dedicou-se à produção açucareira, produção efêmera com queda nos lucros que comprometeu drasticamente sua ampliação. Discutindo sobre os ciclos econômicos no estado, Madeira (2009, p. 7) aponta sobre o último ciclo eufórico, que

[...] na década de 1980, já em outro contexto do capitalismo mundial e da economia brasileira, novamente se apresentou uma esperança de industrialização e desenvolvimento econômico, desta vez relacionada a grandes projetos minerais a serem instalados na Amazônia.

De forma geral, Lopes e outros (2006) compartilham esta ideia, destacando, no entanto, que o Maranhão cumpre papel nas transformações atuais da dinâmica mundializada do capital, identificando dois grandes movimentos, ou o que podemos chamar de duas frentes produtivas. A primeira, a produção desencadeada pelo polo industrial, caracterizado pela modernização conservadora. Este polo tem como maior referência o extinto Programa Grande Carajás (PGC), implantado na década de 1980, sendo a extinta Companhia Vale do Rio Doce, atual empresa Vale, sua coordenadora.

Neste setor se articulam importantes empresas e corporações, tanto nacionais quanto internacionais, para o desenvolvimento de atividades voltadas, principalmente à exploração de recursos naturais, a exemplo de minério, gás e ouro, como já indicado. Porém, apesar do setor industrial desenvolver atividades de transformação, efetivamente suas ações se concentram em um nível primário de industrialização, pois, no estado, estas não alcançam níveis de transformação mais sofisticado ou elaborado.

Como segundo movimento econômico das transformações por que passa o Maranhão na atualidade, Lopes e outros (2006) aponta o agronegócio, que mantém relações explícitas com o primeiro. Estudos mostram que este setor produtivo se amplia de forma intensa rápida e diversificada em todas as regiões do estado.

Importante destacar a participação do Estado, pois sem ele, impossível a redefinição da economia estadual. Como base institucional para a realização do capital, o Estado no Maranhão 
abandonou seu importante papel de fornecedor interno de alimentos, privilegiando o fornecimento de recursos primários para a produção mundial neste processo de acumulação do capital internacional.

Ou seja, no Maranhão, as políticas de desenvolvimento imprimiram deste sempre uma característica de exclusão, não cumprindo com o objetivo de desenvolver de fato o estado, não trazendo melhoria das condições de vida local, mas, ao contrário, aumentando as desigualdades e comprometendo o desenvolvimento de segmentos produtivos socialmente importantes, principalmente na agricultura.

Esta afirmativa nos faz pensar o Maranhão numa perspectiva histórica, onde as formas de planejamento local aparecem sempre reproduzindo uma estagnação em todas as dimensões da organização social. Nesta perspectiva, encontrase a implantação de grandes empreendimentos, como minério de ferro, complexos siderúrgicos, papel e celulose, complexo soja, eucalipto, canade-açúcar, bambu, pecuária de corte, extração de ouro e gás, dentre outros, que, utilizando-se da mesma retórica, a do desenvolvimento, crescimento e geração de emprego, organizam a produção de forma predatória, com a exploração e uso irracional de recursos naturais e do meio ambiente.

Este modelo de produção que garante a inserção de grandes grupos e corporações transnacionais na economia estadual, cuja base é a expansão do capitalismo no estado, trata-se da

\section{[...] primazia dada pela economia estadual ao atendimento das necessidades para a acumulação do capital, negligenciando no processo, as necessidades da sociedade. (AZAR, 2013, p. 47).}

Esta leitura de negligência do Estado acerca dos interesses e necessidades sociais é compartilhada por Mesquita (2011) que destaca que a inserção do Maranhão na dinâmica de mercado globalizado culminou num processo que beneficia alguns setores, ainda que pontualmente. Para o autor, a dinâmica aqui instituída, beneficia

A grupos e segmentos, mas de forma pontual e se restringe, em particular aos intensivos em capital. Os demais (de caráter familiar), ao contrário, são prejudicados ou paralisados por essa lógica neoliberal que iguala segmentos diferentes como a agricultura familiar e o agronegócio da soja e/ou pecuária empresarial. (MESQUITA, 2011, p. 34).

A concepção dos autores acima mencionados tem eco nos dados apresentados pelo Instituto Maranhense de Estudos Econômicos e Cartográficos (IMESC) (apud apud ARAUJO, 2015, p. 40), em 2012, assim como em anos anteriores, o Estado do Maranhão
[...] continua com alta concentração na sua pauta de exportações em três commodities (alumínio, soja e produtos do complexo ferro), que representaram $89,29 \%$ do valor das exportações do Estado do Maranhão [confirmando a análise de Mesquita].

Esta perspectiva sugere um privilégio à produção voltada ao mercado internacional, com benefícios a pequenos segmentos de atividades produtivas superavitárias. Um exemplo disso é o resultado das exportações e importações, no estado, que apresentaram um saldo de US\$ 460,2 milhões, no período de janeiro a julho de 2015 , superando o superávit de US\$325 milhões, referente ao mesmo período em 2014 (MA É..., 2015).

Por outro lado, a agricultura familiar no Maranhão expressa o paradoxo do setor agrícola. Para tanto, tomamos como parâmetro as operações do Programa Nacional de Crédito da Agricultura Familiar (PRONAF), considerado o principal instrumento de crédito público planejado para este segmento produtivo, cujo acesso apresenta-se de forma bastante simbólica, tanto no Maranhão quanto nos demais estados do Nordeste, inclusive com o status de microcrédito.

Sobre este Programa, dados do Banco Central (apud ARAUJO, 2015) têm revelado que, nacionalmente, o valor médio de financiamento por mutuário é de $\mathrm{R} \$ 13.453,38$ (treze mil, quatrocentos e trinta e oito reais). Porém, analisando o país sem a região Nordeste, esta média passa a ser de $R \$ 20$. 980,80 (vinte mil, novecentos e oitenta reais e oitenta centavos), o que significa que o valor médio acessado pela agricultura familiar camponesa no Nordeste é de apenas $R \$ 4.195,20$ (quatro mil, cento e noventa e cinco reais e vinte centavos) (BANCO CENTRAL apud ARAUJO, 2015). Os números apresentados evidenciam, portanto, grande discrepância entre os dois modelos de produção no campo.

Estes valores contribuem para uma conclusão da existência ao limite financeiro imposto ao segmento familiar que trabalha no campo, e impossibilita o seu desenvolvimento. Com isso, estas famílias encontram-se condenadas a não estabelecerem perspectivas mínimas de acumulação, mas ao contrário, de assistiremos à continuidade da desestruturação do sistema de produção, cuja origem é a agricultura local.

Igual preocupação pode ser levantada em relação à reforma agrária, posto que o Estado do Maranhão constitui referência na discussão da questão agrária, pelo papel de destaque que tem na luta pela terra e pelos grandes e intensos conflitos que caracterizam todas as regiões. Como resultado deste processo histórico de luta existe um expressivo quantitativo de famílias assentadas, porém, destacase que apesar das conquistas que este grupo social representa, muitas são as dificuldades que 
caracterizam as condições de vida e de trabalho para o conjunto das famílias que vivem na e da terra, especialmente no que diz respeito às relações de trabalhos constituídas a partir das transformações na dinâmica social e econômica vivenciadas no estado, com a atual dinâmica econômica pautada pelo capital monopolista. Assim, considerando as relações de trabalho uma expressão destas transformações no que diz respeito ao desenvolvimento dependente no Maranhão, trataremos sobre o assunto no item a seguir.

\section{AS RELAÇÕES DE TRABALHO: uma expressão} do desenvolvimento dependente no Maranhão

No que se refere às relações de trabalho estabelecidas no Maranhão a partir da reestruturação do capital desencadeada com a crise da década de 1970, qualquer que seja o setor produtivo, seja a indústria, agricultura, comércio e serviços, estas se caracterizam pela precarização efetiva do trabalho. Os reajustes feitos na economia em geral por conta desta crise, provocaram transformações no mundo do trabalho e desembocam na chamada acumulação flexível, que se apresenta para organizar a produção baseada no uso das tecnologias informatizadas, principalmente, possibilitando com isso o aprofundamento da exploração do trabalho vivo substituído pelo trabalho morto.

Especificamente, a indústria neste estado tem em suas bases produtivas práticas consideradas destrutivas, entendendo-se como tal, o uso irracional de práticas que comprometem o meio ambiente, ou seja, esta produção tem impactado todas as dimensões da vida humana. Nesta perspectiva, podemos dizer, grosso modo, que a produção industrial no Maranhão tem sido um elemento desagregador dos meios de produção e da força de trabalho.

Concretamente, todos os grandes empreendimentos econômicos em andamento nesta unidade federativa, sejam eles industriais ou agropecuários, adotam uma matriz produtiva que apresenta características gerais comuns. Todos, invariavelmente, demandam grandes extensões territoriais, produzem mercadorias para atender demandas externas, utilizam tecnologias moderníssimas e possuem padrão de uso da força de trabalho com pouquíssima empregabilidade.

Por conta desta caracterização geral, também invariavelmente, desencadeiam grandes conflitos e tensões, considerando que para garantir seu padrão produtivo de alta produtividade e grande lucratividade expropriam famílias camponesas da terra e de suas condições de trabalho. Consequentemente, instala-se o conflito e a violência. Para expressar tal contexto, dados da Comissão Pastoral da Terra (CPT) (2014) registram que só em 2013 no Maranhão ocorreram 152 conflitos por terra, alcançando 7.746 famílias. Outra consequência que assume proporções imensuráveis é a expulsão das famílias da terra, ocorrendo grandes e intensos fluxos migratórios, cujos destinos principais são os centros urbanos, sendo que neste contexto

[...] muitas famílias camponesas do estado veem-se condicionadas à migração para os centros urbanos, condição que se desdobra em várias outras, todas, invariavelmente, pautadas na precariedade das condições de vida urbana. Com isso, as cidades sofrem processo de urbanização desordenada, no qual as famílias expulsas do campo passam a ocupar as zonas periféricas, sem acesso aos serviços básicos de habitação, escola e saúde. Em termos de trabalho, passam a desenvolver atividades que exigem pouca ou nenhuma qualificação profissional, compondo, via de regra, o universo da informalidade. (AZAR, 2013, p. 26).

Os grandes empreendimentos econômicos do agronegócio, em tratando dos recursos naturais, apresenta exploração de natureza predatória, o que tem provocado uma crise ambiental sem precedentes no estado, mas também na própria região amazônica, posto que esta produção estadual encontra-se intimamente articulada com as práticas produtivas desenvolvidas nesta região. Sobre isto, muitos são os estudos e denúncias feitas sobre os impactos deste tipo de produção no estado e na região, a exemplo das manifestações e mobilizações realizadas por movimentos sociais e comunidades camponesas diretamente afetadas.

Discutindo as tendências das relações de trabalho no Maranhão, Abreu e outros (2010) concebem a manutenção e aprofundamento da informalidade, da terceirização e da subcontratação como estratégias para a redução dos custos de produção. $\mathrm{E}$, no que diz respeito ao uso da força de trabalho, em geral, estes empreendimentos abusam dos trabalhadores, submetendo-os a precárias condições de trabalho. Neste sentido, há um complexo desrespeito aos direitos trabalhistas, com o não cumprimento das legislações vigentes no país. Articula-se a isso a fragilidade de programas específicos para atender e apoiar estes trabalhadores.

O processo de reestruturação das relações de trabalho no âmbito da reestruturação do capital se materializa através da terceirização, artifício usado de forma abundante por todos os setores produtivos no estado, como mecanismo que tem como função, na dinâmica produtiva estadual, dirimir os custos da produção. Estrategicamente, as empresas repassam a outrem as responsabilidades, principalmente, econômicas, do processo de produção.

Com menores condições, empresas terceirizadas contratam trabalhadores em condições 
precárias, submetendo-os a intensas e extensas jornadas de trabalho e ao não usufruto dos direitos trabalhistas garantidos por lei. Muitas vezes, com contratações temporárias, estes trabalhadores vivenciam a insegurança no trabalho, enfrentam inadequadas e obsoletas máquinas, infraestrutura precária e a insistente ameaça de demissão, cujo respaldo encontra-se na crescente superpopulação relativa.

Sendo o trabalho uma questão não resolvida na constituição brasileira, o que é agravado no Maranhão, historicamente neste estado, os trabalhadores, na busca de atender suas necessidades de reprodução, encontram na informalidade uma das mais importantes estratégias, outra manifestação ou forma do trabalho precarizado. No estado, de forma geral, tal situação apresenta-se agravada com a reorganização produtiva que reduz o uso da força de trabalho assalariado.

Como característica central, esta forma de trabalho apresenta a falta de segurança proporcionada pelos direitos gerais da legislação trabalhista, impondo aos trabalhadores informais exigências e sobrecarga de trabalho que lhes comprometem a tranquilidade que o trabalho deveria possibilitar.

Assim, podemos considerar que a dinâmica das relações sociais, especificamente no que diz respeito à absorção da força de trabalho no âmbito dos grandes empreendimentos econômicos do Maranhão segue a perspectiva do contexto das transformações recentes da macroeconomia determinada pelos países centrais ou desenvolvidos sob a lógica do capital. Lembrando ainda que tais projetos produtivos articulam-se à demanda do capital transnacional, desprestigiando a economia local e as necessidades da população, de modo geral.

\section{CONCLUSÃO}

O Estado do Maranhão apresenta indicadores sociais que the condiciona ocupar, historicamente, o ranking dos estados mais pobres da federação. Histórico é, também, o debate e as iniciativas para o desenvolvimento estadual, o que passa, prioritária e quase exclusivamente, pelo viés da economia. Neste sentido, desde os remotos tempos da colonização, o estado cumpre papel junto à divisão nacional e internacional do trabalho, seja na produção cíclica das culturas do arroz e do algodão do Brasil colônia, para atender o mercado internacional; seja na produção de gêneros alimentícios para a emergente industrialização nacional; ou ainda, como na atualidade, com a produção de commodities agrícolas, aliada à economia financeira.

Em comum a todas as iniciativas, a retórica do desenvolvimento estadual. Importante observar que o desenvolvimento proposto segue determinações históricas do desenvolvimento e consolidação da acumulação do capital, com destaque para o capital transnacional, posto que desde sempre a economia estadual segue os preceitos dos interesses internacionais, produzindo, de uma maneira ou de outra, para atender às necessidades e exigências da macroeconomia.

Nesta condição, portanto, o desenvolvimento proposto pelo Estado maranhense, indubitavelmente, apresenta características de dependência, condicionando-se, neste sentido, às variantes políticas e econômicas da dinâmica geral do capital. De forma geral, as consequências e impactos destes processos recaem, invariavelmente, nas relações de trabalho, afetando de forma contundente a classe trabalhadora, que no Maranhão, apresenta características particulares de fragilidade e precariedade.

Especificamente, no contexto atual das transformações no mundo do trabalho proporcionadas pela reestruturação da produção, as relações de trabalho neste estado apresentam-se manifestas nas formas mais cruéis para o conjunto da classe trabalhadora, expressas, principalmente, pela terceirização e pela informalidade. No conjunto das práticas produtivas de todos os setores econômicos reina o abuso, principalmente da utilização predatória dos recursos naturais, impactando destrutivamente o meio ambiente, com especial destaque a imposição de relações de trabalho que, de tão precarizadas, comprometem a reprodução social da classe trabalhadora, o que muito explicita o modelo de desenvolvimento aqui adotado, o dependente.

\section{REFERÊNCIAS}

ABREU, M. M. et al. Metamorfoses e tendências das relações de trabalho no Maranhão. In: CONGRESSO BRASILEIRO DE ASSISTENTES SOCIAIS, 13., 2010, Brasília, DF. Anais... Brasília, DF: CFESS/ ABEPSS/ENESSO, 2010.

ARAUJO, F. E. Desafios da Reforma agrária, no contexto do desenvolvimento dependente no estado do Maranhão: um estudo de caso da Microrregião de Chapadinha. 2015. 162 f. Dissertação (Mestrado em Agroecossistemas) - Programa de Pós-Graduação em Agroecossistemas, Universidade Federal de Santa Catarina, Florianópolis, 2015.

AZAR, Z. S. Relações de trabalho e resistência camponesa no desenvolvimento dependente no Maranhão: o assentamento Califórnia como Uma Expressão. 2013. 343 f. Tese (Doutorado em Políticas Públicas) - Programa de Pós Graduação em Políticas Públicas, Universidade Federal do Maranhão, São Luís, 2013. 


\section{COMISSÃO PASTORAL DA TERRA. Conflitos no campo - Brasil 2013. Goiânia, 2014.}

LEAL, A. L. Amazônia: o aspecto político da questão mineral. 1988. Dissertação (Mestrado em Planejamento Regional) - Núcleo de Altos Estudos Amazônicos, Mestrado em Planejamento do Desenvolvimento, Universidade Federal do Pará, Belém, 1988.

LOPES, J. B. L. et al. Transformações contemporâneas e sistema de controle social nas relações campo e cidade: trabalho, luta social e prática do Serviço Social no Maranhão. São Luís, 2006. Projeto de pesquisa.

MA É $2^{\circ}$ do Nordeste em ranking de VBP agropecuária, diz Ministério. G1 MA, São Luís, 2015. Disponível em:<http://g1.globo.com/ma/maranhao/ noticia/2015/01/ma-e-2-do-nordeste-em-ranking-devbp-agropecuaria-diz-ministerio.html>. Acesso em $17 / 01 / 2015$.

MADEIRA, W. do V. "Euforias Maranhenses" e o mito do desenvolvimento econômico. In: SEMINÁRIO INTERNACIONAL SOBRE O DESENVOLVIMENTO REGIONAL DO NORDESTE, 1., 2011, Recife. Anais... Recife: CICEF/UFPE, 2011. Disponível:<http://www.desenvolvimentoregional. com.br/sessao.php?tpt=G>. Acesso em: 4 jun. 2011.

MARINI, R. M. Dialética da dependência. In: TRASPADINI, R.; STÉDILE, J. P. (Orgs.). Ruy Mauro Marini: vida e obra. 1. ed. São Paulo: Expressão Popular, 2005

MESQUITA, B. A. de. O desenvolvimento desigual da agricultura: a dinâmica do agronegócio e da agricultura familiar. São Luís: EDUFMA, 2011.

PRADO JR, C. A questão agrária e a revolução brasileira. In: STÉDILE, J. P. (Org). A questão agrária no Brasil: o debate tradicional - 1500-1960. São Paulo: Expressão Popular, 2005.

\section{Zaira Sabry Azar}

Assistente Social

Doutora em Políticas Públicas pela Universidade Federal do Maranhão (UFMA) e Professora do Departamento do Serviço Social da UFMA

E-mail: zairasabry@hotmail.com

\section{Francisco Elias de Araújo}

Engenheiro Agrônomo

Mestre em Agroecossistemas pela Universidade Federal de Santa Catarina (UFSC)

Militante do Movimento dos Trabalhadores Rurais Sem

Terra (MST)

E-mail: earaujo013@gmail.com
Universidade Federal do Maranhão - UFMA

Cidade Universitária Dom Delgado

Av. dos Portugueses, n. 1966, Bacanga, São Luís/MA CEP: $65085-580$ 